\title{
Etifoxine promotes glial-derived neurotrophic factor-induced neurite outgrowth in PC12 cells
}

\author{
XIANG ZHOU ${ }^{1 *}$, XINHUA HE ${ }^{2,3 *}$, BO HE ${ }^{1}$, ZHAOWEI ZHU ${ }^{1}$, CANBIN ZHENG $^{1}$, JIAN XU $^{4}$, \\ LI JIANG ${ }^{1}$, LIQIANG GU ${ }^{1}$, JIAKAI ZHU ${ }^{1}$, QINGTANG ZHU ${ }^{1}$ and XIAOLIN LIU ${ }^{1}$ \\ ${ }^{1}$ Department of Microsurgery and Orthopedic Trauma, The First Affiliated Hospital of Sun Yat-sen University, Guangzhou, \\ Guangdong 510080; ${ }^{2}$ Department of Physiology, Shangtou University Medical College, Shantou, Guangdong 515041; \\ ${ }^{3}$ Department of Neurobiology, Southern Medical University, Guangzhou, Guangdong 510515; \\ ${ }^{4}$ Department of Reproductive Medicine, The First Affiliated Hospital of Sun Yat-sen University, \\ Guangzhou, Guangdong 510080, P.R. China
}

Received January 14, 2013; Accepted April 30, 2013

DOI: $10.3892 / \mathrm{mmr} .2013 .1474$

\begin{abstract}
Nerve regeneration and functional recovery are major issues following nerve tissue damage. Etifoxine is currently under investigation as a therapeutic strategy for promoting neuroprotection, accelerating axonal regeneration and modulating inflammation. In the present study, a well-defined PC12 cell model was used to explore the underlying mechanism of etifoxine-stimulated neurite outgrowth. Etifoxine was found to promote glial-derived growth factor (GDNF)-induced neurite outgrowth in PC12 cells. Average axon length increased from $50.29 \pm 9.73$ to $22.46 \pm 5.62 \mu \mathrm{m}$ with the use of etifoxine. However, blockage of GDNF downstream signaling was found to lead to the loss of this phenomenon. The average axon length of the etifoxine group reduces to a normal level after the blockage of the GDNF family receptor $\alpha 1(\mathrm{GFR} \alpha 1)$ and receptor tyrosine kinase (RETS) receptors $(27.46 \pm 3.59 \mathrm{vs} .22 .46 \pm 5.62 \mu \mathrm{m}$ and $25.31 \pm 3.68 \mu \mathrm{m}$ vs. $22.46 \pm 5.62 \mu \mathrm{m}$, respectively, $\mathrm{p}>0.05$ ). In addition, etifoxine markedly increased GDNF mRNA and protein expression (1.55- and 1.36-fold, respectively). However, blockage was not found to downregulate GDNF expression. The results of the current study demonstrated that etifoxine stimulated neurite outgrowth via GDNF, indicating that GDNF represents a key molecule in etifoxine-stimulated neurite outgrowth in $\mathrm{PC} 12$ cells.
\end{abstract}

Correspondence to: Professor Xiaolin Liu or Professor Qingtang Zhu, Department of Microsurgery and Orthopedic Trauma, The First Affiliated Hospital of Sun Yat-sen University, 58 Zhongshan Er Road, Guangzhou, Guangdong 510080, P.R. China

E-mail: gzxiaolinliu@hotmail.com

E-mail: qtzhu@qq.com

${ }^{*}$ Contributed equally

Key words: etifoxine, neurite outgrowth, $\mathrm{PC} 12$

\section{Introduction}

Traumatic injury to peripheral nerves results in considerable loss of sensory and motor function, decreasing quality of life in patients (1). Peripheral nerve injuries substantially impact quality of life through loss of function and increased risk of secondary disabilities from falls, fractures and other injuries. Several research groups have attempted to improve the regeneration of traumatized nerves by developing favorable microsurgical techniques. However, clinicians soon noted that despite advancement in these techniques, complete recovery is rarely achieved $(2,3)$. Therefore, complete recovery remains an important clinical challenge for the improvement of functional recovery following peripheral nerve injury. In a discussion of future trends in the management of brachial plexus injuries, Birch hypothesized that the administration of nerve growth factor may represent a useful treatment strategy (4).

Neurotrophic factors are important in a number of biological processes, including survival, proliferation, differentiation and apoptosis of neurons in the nervous system (5-7). However, direct use of trophic factors in clinical practice is extremely challenging as they are difficult to administer and have severe side effects (8). However, molecules that easily diffuse into nerve tissues, including ligands of the progesterone and thyroid hormone receptors, and immunophilins, have beneficial effects on peripheral nerves in various experimental lesion and disease models (9-12). We hypothesize that clinically established drugs may be suitable to elevate trophic factor levels to improve the outcome of peripheral nerve injuries.

Previous studies have demonstrated that the drug, etifoxine (2-ethylamino-6-chloro-4-methyl-4-phenyl-4H-3, 1-benzoxazine hydrochloride; Stresam; Biocodex, Moscow, Russia), exerts anxiolytic effects by targeting GABAA receptors and translocator protein (TSPO; $18 \mathrm{kDa})(8,13)$. TSPO is mainly localized in the outer mitochondrial membrane and has multiple functions (14). Following peripheral nerve injury, TSPO expression is transiently increased in a number of cells, including dorsal root ganglia (DRG) neurons, 
Schwann cells and macrophages $(15,16)$. In addition, TSPO ligands have been identified to exert neuroprotective effects and reduce neural inflammation in the CNS $(17,18)$. In rats, ligand binding stimulates the cholesterol transfer function of TSPO. According to the concept of neurosteroids (19), this mechanism is likely to be responsible for the increase of neurosteroid levels observed in the brain $0.5 \mathrm{~h}$ following administration of $50 \mathrm{mg} / \mathrm{kg}$ etifoxine (13). Neurosteroids, including pregnenolone (PREG), progesterone (PROG) and dehydroepiandrosterone (DHEA) have been demonstrated to be regulated by the activation of TSPO (20-23). Cholesterol and neurosteroids are important for neuronal regeneration (24). For example, cholesterol deficiency inhibits axonal branching and promotes axonal degeneration $(25,26)$. DHEA enhances functional recovery and increases the number of nerve fibers in the sciatic nerve following a crush injury (27) and PROG has been reported to increase neurite outgrowth in vitro and in vivo $(28,29)$. However, at present, it remains unknown whether administration of etifoxine leads to enhanced neurite outgrowth and the underlying mechanisms involved in this process are undefined.

Glial cell line-derived neurotrophic factor (GDNF) was previously identified in conditioned media from a glial cell line based on its ability to promote survival and increase cell size and neurite length in mesencephalic dopaminergic neurons in culture $(30,31)$. As no effect was observed on GABAergic neurons, GDNF was originally hypothesized to be a selective survival factor for the nigrostriatal dopaminergic neurons that degenerate in Parkinson's disease (32). However, additional studies have revealed that GDNF also supports the survival of spinal motor neurons (33) and brain noradrenergic neurons (34). GDNF also regulates the survival, migration and differentiation of several peripheral neurons (35). The neuroprotective effects of GDNF on dopaminergic neurons has led to studies on the effects of GDNF administration in animal models of Parkinson's disease $(36,37)$. Using various approaches for the administration of the trophic factor, these studies demonstrated that the administration of GDNF following lesion generation increases the number of dopaminergic cell bodies in the substantia nigra, the density of dopaminergic fibers and dopamine levels in the striatum. Administration of GDNF also induces the recovery of motor impairments (38). Finally, GDNF has also been observed to exhibit neuroprotective functions under conditions leading to the death of other types of neurons. Since GDNF has been found to be involved in a considerable number of effects in the nervous system, the present study aimed to determine whether GDNF plays a role in etifoxine-stimulated neurite outgrowth (8).

In the present study, a well-defined PC12 cell model was used to test whether etifoxine is involved in axon regeneration. Etifoxine was observed to lead to increased neurite outgrowth, while GDNF expression increased following 3 days of treatment and GDNF receptor inhibitor blocked the effects of etifoxine on nerve regeneration. These results demonstrate a role of etifoxine in GDNF-induced neurite outgrowth.

\section{Materials and methods}

Cell culture and measurement. Rat PC12 cells were cultured on collagen-coated plates $\left(5 \mu \mathrm{g} / \mathrm{cm}^{2}\right)$ in DMEM supplemented with
$5 \%$ horse serum, $10 \% \mathrm{FBS}, 100 \mathrm{U} / \mathrm{ml}$ penicillin and $100 \mu \mathrm{g} / \mathrm{ml}$ streptomycin. Cells were counted in 6 fields throughout the entire culture dish. At least 400 cells were counted per sample. Experiments were repeated at least three times. Neuronal-like outgrowth was determined on day 10 using the Olympus IX81 microscope and U-CMAD 3 camera (Olympus, Tokyo, Japan). Cell body size and axon length were analyzed using the image analysis software version 3.2 (SIS, Münster, Germany). PC12 cells with axons longer than the average cell diameter were included for data collection. The two-tailed Mann-Whitney U test (GraphPad Prism 4; GraphPad Software, San Diego, CA, USA) was used for statistical assessment of GDNF release and its bioactivity on the axonogenesis of PC12 cells.

RNA isolation. To collect total RNA, $2 \times 10^{6}$ cells were seeded onto $10-\mathrm{cm}$ diameter dishes in $8 \mathrm{ml}$ growth medium. Cultures were maintained at $37^{\circ} \mathrm{C}$ in a humidified atmosphere of $5 \%$ $\mathrm{CO}_{2} / 95 \%$ air. Media were replaced with the drug of interest. Following 6 days, total RNA was isolated using an Isogen kit (Nippon Gene, Tokyo, Japan), according to the manufacturer's instructions. RNA quantity and purity were determined by spectrophotometry (Beckman DU-65; Beckman Coulter, Miami, FL, USA).

$R T-P C R$. RT-PCR was performed using an RNA PCR kit (AMV; version 2.1) according to the manufacturer's instructions and a PCR Thermal Cycler (both Takara Bio, Inc., Shiga, Japan). First-strand cDNA was synthesized from total RNA (1 mg) using AMV reverse transcriptase XL primed by 50 pmol random 9-mers (Takara Bio, Inc.). The first-strand reaction was performed as follows: $30^{\circ} \mathrm{C}$ for $10 \mathrm{~min}, 50^{\circ} \mathrm{C}$ for $30 \mathrm{~min}, 99^{\circ} \mathrm{C}$ for $5 \mathrm{~min}$ and $58^{\circ} \mathrm{C}$ for $5 \mathrm{~min}$. RT reaction products $(10 \mathrm{ml})$ were utilized as templates in the PCR with $0.2 \mathrm{~mm}$ each of the following primers: 5'-GGTCTACGGAGAGACCGATCCGAGGTGC-3' and 5'-TCTCTGGAGCCAGGGTCAGATACATC-3' for GDNF, 5'-TGAAGGTCGGTGTCAACGGATTTGGC-3' and 5'-CATGTAGGCCATGAGGTCCACCAC-3' for GAPDH. PCR products were separated by precast $2 \%$ agarose gel (Daiichi Pure Chemicals, Tokyo, Japan) electrophoresis and visualized by SYBR Green 2 (FMC Bio-Products, Rockland, ME, USA) staining on a UV transilluminator. The signal intensity of the PCR products was determined by ImageJ. The amounts of GDNF PCR product were determined using calculations based on the intensity of the product from the paired GAPDH reactions.

Western blot analysis. Western blot analysis was performed using antibodies to detect total GDNF proteins (4G10; Upstate Biotechnology, Lake Placid, NY, USA). PC12 cells were collected using ice-cold phosphate-buffered saline and solubilized in the sample buffer [100 mM Tris-HCl (pH 6.8), $20 \%$ glycerol and 4\% SDS]. Total protein in each sample was adjusted to be the same amount for all samples. Following the addition of 1,4-dithiothreitol, samples were boiled for $5 \mathrm{~min}$. Proteins were separated by SDS-polyacrylamide gel electrophoresis and transblotted onto polyvinylidene difluoride membranes. The blots were blocked with $10 \%$ skimmed milk for $2 \mathrm{~h}$ at room temperature and then immunoblotted with rabbit anti-rat antibodies against GDNF and GAPDH (1:100) 
overnight. After three washes, the blots were subsequently incubated with a goat anti-rabbit peroxidase conjugated secondary antibody $(1: 1,000)$ for $1 \mathrm{~h}$ at room temperature. Then the specific binding was detected with the enhanced chemiluminescence system.

Statistical analysis. All numerical data are presented as the mean \pm SE. The results were subjected to statistical analysis using a student version of SPSS 11.5 software for Windows. $\mathrm{P}<0.05$ was considered to indicate a statistically significant difference.

\section{Results}

Etifoxine induces neuronal-like outgrowth of PC12 cells. To detect the effect of etifoxine, the number of PC12 cells demonstrating axonogenesis, their cell body sizes and the overall length of outgrown fibers were determined. Fig. 1 presents the biological activity of etifoxine; consistent with previous studies on the mechanism by which etifoxine promotes neurite extension, a marked increase in neuronal-like outgrowth was observed 10 days following the application of etifoxine (Fig. 1B). Next, to determine whether etifoxine affected the cells through the GDNF receptors, GDNF family receptor $\alpha 1$ (GFR $\alpha 1)$ and rearranged during transfection (RET), cultures were treated with specific compounds known to block GDNF signaling. In contrast to the effects of etifoxine, the administration of phosphoinositide phospholipase C (PI-PLC), which blocks signaling via GFR $\alpha 1$ or PRI-1 (both Calbiochem, La Jolla, CA, USA), a specific RET receptor tyrosine kinase inhibitor, induced poor neuronal-like processes in PC12 cells following 10 days of cultivation.

Statistical assessment of neuronal-like outgrowth of PC12 cells revealed significant axonogenesis induction following administration of GDNF $(\mathrm{P}<0.05 ; 50.29 \pm 9.73 \mu \mathrm{m})$ in comparison with saline $(22.46 \pm 5.62 \mu \mathrm{m}$; Fig. 2A). However, the use of PI-PLC and PRI-1 following administration of etifoxine did not significantly induce neuronal-like processes in the PC12 cells $(27.46 \pm 3.59$ and $25.31 \pm 3.68 \mu \mathrm{m}$, respectively). These observations indicate that following blockage of GDNF downstream, etifoxine exerts no effect on neuronal-like outgrowth in $\mathrm{PC} 12$ cells.

The average cell body size of PC12 was also determined during the culture period as changes in morphology and size of the cells indicate higher metabolic activity induced by external stimuli. Cell body sizes were measured in all the groups. The average PC12 cell body size increased following exposure to etifoxine for 10 days in comparison with the cell body size of those incubated with saline (Fig. 2B). However, a decline in the PC12 cell body size was noted in the PI-PLC and PRI-1 treatment groups compared with the etifoxine group (Fig. 2B), however, these slight changes were not significant.

Expression of GDNF mRNA by drug treatment. To address the mechanism of neuronal-like outgrowth in PC12 cells induced by etifoxine, the expression of GDNF mRNA was measured by RT-PCR using GDNF-specific primers. Following treatment with etifoxine, GDNF mRNA expression levels increased 1.55-fold compared with saline treatment; however, the differ-
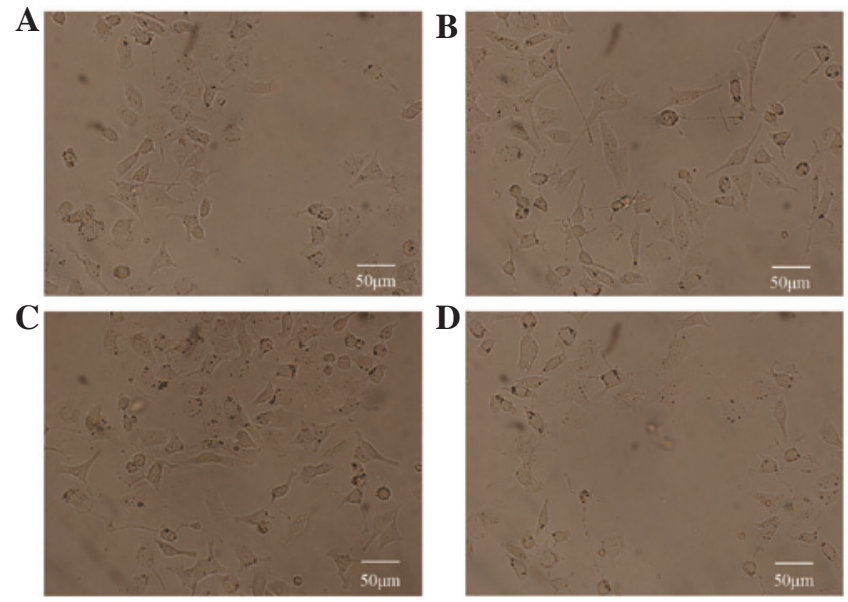

Figure 1. Microscopic view of PC12 cells in (A) saline, (B) etifoxine, (C) PI-PLC + etifoxine and (D) PRI-1 + etifoxine following cultivation for 10 days. Cells treated with etifoxine alone demonstrated a significant increase in axonal sprouting. Cells treated with PI-PLC or PRI-1 in combination with etifoxine demonstrated poor axonogenesis. PI-PLC, phosphoinositide phospholipase $\mathrm{C}$.

A

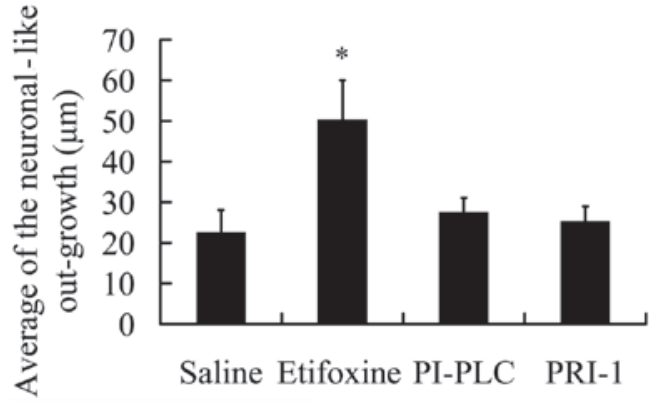

B

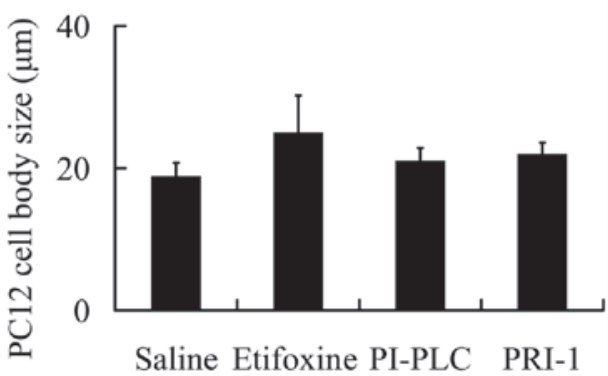

Figure 2. Comparison of the average (A) axon length of PC12 cells and (B) diameter of the PC12 cell bodies 10 days following the application of each agent. Data points represent the mean \pm SD of PC12 cell cultures in media $(n=8)$. A two-tailed Mann-Whitney U test was used for statistical assessment of differential axonogenesis. ${ }^{*} \mathrm{P}<0.001$ compared with the saline group. PI-PLC, phosphoinositide phospholipase C.

ence compared with etifoxine group was not identified to be significant (Fig. 3). These results were consistent with the results of the outgrown fibers demonstrating that etifoxine increased the neuronal-like outgrowth of PC12 cells. Next, we determined whether treatment with PI-PLC and PRI-1 leads to a sustained decrease in GDNF mRNA levels. Cells were treated with etifoxine and fresh media were added with or without PI-PLC and PRI-1. However, GDNF expression levels remained high following the administration of PI-PLC and PRI-1 (1.50- and 1.43-fold, respectively; $\mathrm{P}<0.05)$. These results 


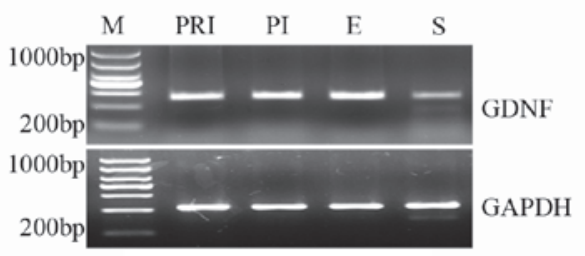

B

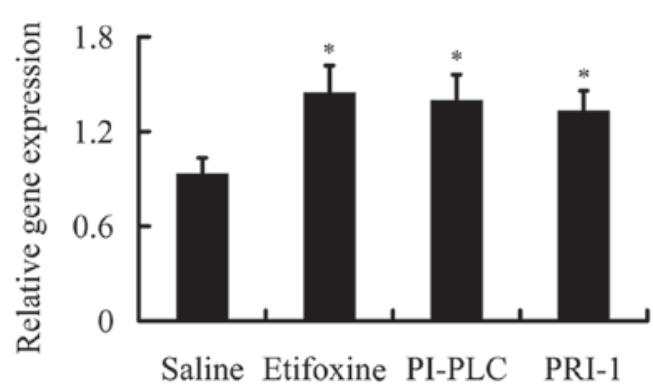

Figure 3. RT-PCR analysis of mRNA expression of GDNF mRNA in drug-treated PC12 cells. A representative blot is presented and the data are presented as the mean $\pm \mathrm{SD}$ of PC12 cell cultures in media $(\mathrm{n}=8)$. A two-tailed Mann-Whitney U test was used for statistical assessment of differential axonogenesis. ${ }^{*} \mathrm{P}<0.001$ compared with the saline group. $\mathrm{M}$, marker; $\mathrm{S}$, saline; E, etifoxine; PI, etifoxine + PI; PRI, etifoxine + PRI; GDNF, glial-derived growth factor; PI-PLC, phosphoinositide phospholipase C.

A

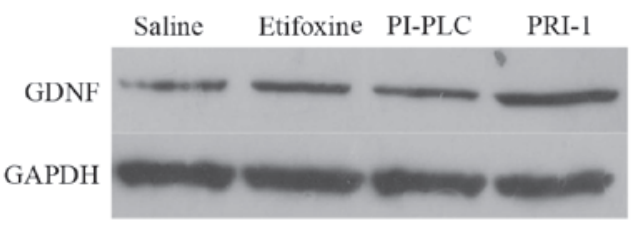

B

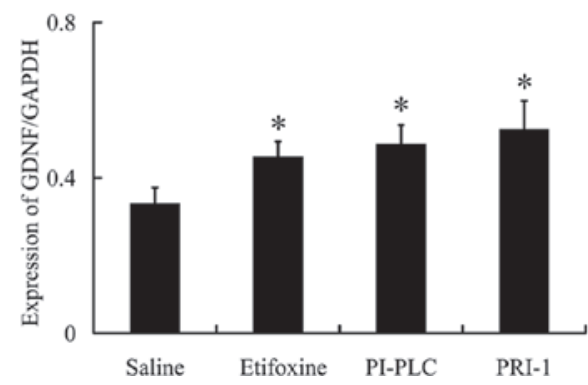

Figure 4. GDNF levels in drug-treated PC12 cells. A representative result is presented and the data are presented as the mean \pm SD of PC12 cell cultures in media $(\mathrm{n}=8)$. A two-tailed Mann-Whitney $\mathrm{U}$ test was used for statistical assessment of differential axonogenesis. ${ }^{\mathrm{P}}<0.001$ compared with the saline group. $\mathrm{M}$, marker; S, saline; E, etifoxine; PI, etifoxine + PI; PRI, etifoxine + PRI; GDNF, glial-derived growth factor; PI-PLC, phosphoinositide phospholipase C.

demonstrate the opposite result on the outgrown fibers (Fig. 3), which indicate that the use of PI-PLC and PRI-1 does not change the expression levels of GDNF in PC12 cells.

Expression of GDNF protein by drug treatment. Finally, the effects of drug treatment on GDNF protein expression were investigated. In addition, the effect of etifoxine on GDNF expression was measured in PC12 cells by western blot analysis. While the use of etifoxine increased GDNF levels in PC12 cells (Fig. 4), this effect was not inhibited by the use of PI-PLC and PRI-1. Following the administration of etifoxine, GDNF protein expression increased by $\sim 1.36$-fold compared with the saline-treated group. Use of the GFR $\alpha 1$ inhibitor, PI-PLC, led to a higher expression of GDNF (1.46-fold vs. saline). In addition, the RET inhibitor, PRI-1, was observed to result in increased expression of GDNF (1.57-fold vs. saline); however, the difference compared with etifoxine was not identified to be significant (Fig. 4).

\section{Discussion}

Statistical analysis of the average length of fibers in PC12 cells following exposure to etifoxine revealed neuronal-like outgrowth increased up to 2.23-fold following day 10, resulting in numerous partially arborescent axons. By contrast, PC12 cultivation in supernatant with PI-PLC and PRI-1 induced poor neuronal-like processes following 10 days of cultivation. These observations indicate a marked in vitro bioactivity of etifoxine, which is capable of inducing signaling in PC12 cells for neuronal-like processes, indicating a potential clinical application for etifoxine.

Previous studies have demonstrated that TSPO may regulate outgrowth by increasing ATP availability, an essential factor for neurite growth (39-41). TSPO associates with the mitochondrial permeability transition pore (42), which enables the respiratory chain to create the transmembrane electrochemical gradient that drives ATP synthesis. By this mechanism, TSPO may regulate a number of biological functions in cells. In addition, TSPO may also affect neurite outgrowth by controlling the rate of neurosteroid formation (43). Mitochondrial TSPO regulates the transport of cholesterol from the outer to inner membrane, which is the rate-limiting step in steroid production (19). The neurosteroids, PREG, PROG and DHEA, play major roles in neuronal regeneration. PROG increases neurite outgrowth of DRG explants, promotes regeneration in cryolesioned sciatic nerves and remyelination of regenerated nerve fibers $(28,29)$. PREG and PROG levels increase in injured sciatic nerves and have neurotrophic effects $(29,44)$. In addition, estradiol (a type of steroid) leads to increased expression of GDNF. We hypothesize that estradiol rapidly increases $\mathrm{Ca}^{2+}$ levels, which is followed by CREB phosphorylation. CREB phosphorylation ultimately leads to increased expression of GDNF (45). However, at present, the mechanism by which TSPO activation leads to increased GDNF expression in PC12 cells remains unknown. One hypothesis is that TSPO activation leads to increased steroidogenesis. Increased steroids may affect gene expression through CREB phosphorylation. Thus, neurite outgrowth increases, consistent with current observations in which treatment with etifoxine led to an increase in GDNF expression, which initiated its receptors resulting in poor regeneration without alterations in GDNF expression.

GDNF is a glycosylated, disulfide-bonded homodimer with a molecular weight of 33-45 $\mathrm{kDa}$. The monomer has a molecular weight of $16 \mathrm{kDa}$ following deglycosylation (31) and it regulates cellular activity through interaction with glycosylphosphatidylinositol-anchored cell surface receptors. GFR $\alpha 1$, which may signal through the transmembrane RET receptor or neural cell adhesion molecule (NCAM), promotes cell survival, neurite outgrowth and synaptogenesis (32). GFR $\alpha 1$ lacks transmembrane and intracellular domains (46) and therefore, GFR $\alpha 1$ functions only as a binding receptor, requiring a transduction receptor for signaling. GFR $\alpha 1$ signals 
through transmembrane RET tyrosine kinase, which in turn may activate several intracellular signaling cascades, including Ras/mitogen-activated protein kinase, phosphatidylinositol 3-kinase/Akt and PLCg pathways (47).

An additional signaling receptor for GFR $\alpha 1$ is NCAM (48), which mediates neurite outgrowth induced by GDNF in cultured hippocampal neurons (49). In the absence of GDNF, GFR $\alpha 1$ binds NCAM, inhibiting cell adhesion mediated by homophilic NCAM interaction. However, in the presence of GDNF, the GFR $\alpha 1 /$ GDNF/NCAM complex mediates cell adhesion by a mechanism involving Fyn kinase and focal adhesion kinase (46). Considering the discussed observations, the physiological significance of the functions and roles mediated through the GDNF-GFR $\alpha 1$-RET pathway was reinforced by the observation that RET-independent GFR $\alpha 1$ is dispensable for organogenesis and nerve regeneration in vivo, indicating that trans- and GFR $\alpha 1$-dependent NCAM signaling plays a minor physiological role (50). Thus, RET-mediated signaling in the nervous system is important for the survival and differentiation of cancer, but also in human forms of cancer where excessive activation of RET has been observed.

The current study demonstrates that treatment with etifoxine in PC12 cells stimulated GDNF expression, which correlated with neurite outgrowth. In addition, the results indicate that following inhibition of the GDNF receptor, GFR $\alpha 1-R E T$, the increase in neurite outgrowth was lost. These results indicate that in PC12 cells, the GDNF-GFR $\alpha 1-\mathrm{RET}$ pathway was dominant for etifoxine-induced neurite outgrowth. As observed in this study, RET blockage resulted in total abolition of neurite growth in etifoxine-treated PC12 cells, demonstrating that for etifoxine-induced neurite outgrowth, this pathway is important.

We hypothesize that the bioactivity of GDNF is represented by PC12 cell body size since changes in morphology and size of the cells indicate higher metabolic activity induced by external stimuli (51). A slight, but not significant, increase in the average cell body size was demonstrated following 3 and 10 days of GDNF cultivation compared with PC12 cells cultivated in medium with extremely low GDNF content, indicating that GDNF is capable of inducing internal signaling pathways in PC12 cells. However, cell body size may not be an appropriate marker for GDNF or, in general, neurotrophic factor (NTF) bioactivity.

In conclusion, the results of the present study indicate that etifoxine markedly enhances neurite outgrowth by increasing GDNF expression. Etifoxine fulfills the criteria of a drug that is clinically useful for the treatment of altered peripheral axons: i) easy diffusion into nerve tissues; ii) selective modulation of inflammatory responses to injury; iii) able to increase the expression of neurotrophic factors; iv) suitable for long-term use $(52,53)$ and (v) convenient administration. Considering the important benefits of etifoxine, etifoxine treatment may represent a promising strategy for the treatment of peripheral nerve injury.

\section{Acknowledgements}

The authors would like to thank Dr Weihong Yang for technical assistance. The current study was supported by grants from the National High Technology Research and Development Program of China (no. 2012AA020507), the National Nature Science Grant of China (no. 30700847), Medical Scientific Research Foundation of Guangdong Province, China (B2011176), the Key Project of Nature Science Grant of Guangdong China (no. 9251008901000017) and the China Postdoctoral Science Foundation (no. 20110490929).

\section{References}

1. IJkema-Paassen J, Jansen K, Gramsbergen A and Meek MF: Transection of peripheral nerves, bridging strategies and effect evaluation. Biomaterials 25: 1583-1592, 2004.

2. Kline DG and Hudson AR: Vertebral artery compression. J Neurosurg 83: 759, 1995.

3. Lundborg G: Intraneural microcirculation. Orthop Clin North Am 19: 1-12, 1988.

4. Birch R: Surgery for brachial plexus injuries. J Bone Joint Surg Br 75: 346-348, 1993.

5. Airaksinen MS and Saarma M: The GDNF family: signalling, biological functions and therapeutic value. Nat Rev Neurosci 3: 383-394, 2002.

6. Baloh RH, Enomoto H, Johnson EJ and Milbrandt J: The GDNF family ligands and receptors - implications for neural development. Curr Opin Neurobiol 10: 103-110, 2000.

7. Chu TH and $\mathrm{Wu} \mathrm{W}$ : Neurotrophic factor treatment after spinal root avulsion injury. Cent Nerv Syst Agents Med Chem 9: 40-55, 2009.

8. Girard C, Liu S, Cadepond F, et al: Etifoxine improves peripheral nerve regeneration and functional recovery. Proc Natl Acad Sci USA 105: 20505-20510, 2008.

9. Barakat-Walter I: Role of thyroid hormones and their receptors in peripheral nerve regeneration. J Neurobiol 40: 541-559, 1999.

10. Gold BG, Udina E, Bourdette D and Navarro X: Neuroregenerative and neuroprotective actions of neuroimmunophilin compounds in traumatic and inflammatory neuropathies. Neurol Res 26: 371-380, 2004.

11. Melcangi RC and Garcia-Segura LM: Therapeutic approaches to peripheral neuropathy based on neuroactive steroids. Expert Rev Neurother 6: 1121-1125, 2006.

12. Schumacher M, Guennoun R, Mercier G, et al: Progesterone synthesis and myelin formation in peripheral nerves. Brain Res Brain Res Rev 37: 343-359, 2001.

13. Verleye M, Akwa Y, Liere P, et al: The anxiolytic etifoxine activates the peripheral benzodiazepine receptor and increases the neurosteroid levels in rat brain. Pharmacol Biochem Behav 82: 712-720, 2005.

14. Papadopoulos V, Baraldi M, Guilarte TR, et al: Translocator protein $(18 \mathrm{kDa})$ : new nomenclature for the peripheral-type benzodiazepine receptor based on its structure and molecular function. Trends Pharmacol Sci 27: 402-409, 2006.

15. Karchewski LA, Bloechlinger S and Woolf CJ: Axonal injury-dependent induction of the peripheral benzodiazepine receptor in small-diameter adult rat primary sensory neurons. Eur J Neurosci 20: 671-683, 2004.

16. Lacor P, Benavides J and Ferzaz B: Enhanced expression of the peripheral benzodiazepine receptor (PBR) and its endogenous ligand octadecaneuropeptide (ODN) in the regenerating adult rat sciatic nerve. Neurosci Lett 220: 61-65, 1996.

17. Torres SR, Frode TS, Nardi GM, et al: Anti-inflammatory effects of peripheral benzodiazepine receptor ligands in two mouse models of inflammation. Eur J Pharmacol 408: 199-211, 2000.

18. Veiga S, Azcoitia I and Garcia-Segura LM: Ro5-4864, a peripheral benzodiazepine receptor ligand, reduces reactive gliosis and protects hippocampal hilar neurons from kainic acid excitotoxicity. J Neurosci Res 80: 129-137, 2005.

19. Baulieu EE: Neurosteroids: of the nervous system, by the nervous system, for the nervous system. Recent Prog Horm Res 52: 1-32, 1997.

20. Ferzaz B, Brault E, Bourliaud G, et al: SSR180575 (7-chloro-N, 5-trimethyl-4-oxo-3-phenyl-3,5-dihydro-4H-pyridazino[4,5-b]in dole-1-acetamide), a peripheral benzodiazepine receptor ligand, promotes neuronal survival and repair. J Pharmacol Exp Ther 301: 1067-1078, 2002.

21. Korneyev A, Pan BS, Polo A, Romeo E, Guidotti A and Costa E: Stimulation of brain pregnenolone synthesis by mitochondrial diazepam binding inhibitor receptor ligands in vivo. J Neurochem 61: 1515-1524, 1993 
22. Lacor P, Gandolfo P, Tonon MC, et al: Regulation of the expression of peripheral benzodiazepine receptors and their endogenous ligands during rat sciatic nerve degeneration and regeneration: a role for PBR in neurosteroidogenesis. Brain Res 815: 70-80, 1999.

23. Papadopoulos V, Amri H, Boujrad N, et al: Peripheral benzodiazepine receptor in cholesterol transport and steroidogenesis. Steroids 62: 21-28, 1997.

24. Schumacher M, Robel P and Baulieu EE: Development and regeneration of the nervous system: a role for neurosteroids. Dev Neurosci 18: 6-21, 1996.

25. Fan QW, Yu W, Gong JS, et al: Cholesterol-dependent modulation of dendrite outgrowth and microtubule stability in cultured neurons. J Neurochem 80: 178-190, 2002.

26. Fan QW, Yu W, Senda T, Yanagisawa K and Michikawa M: Cholesterol-dependent modulation of tau phosphorylation in cultured neurons. J Neurochem 76: 391-400, 2001.

27. Gudemez E, Ozer K, Cunningham B, Siemionow K, Browne E and Siemionow M: Dehydroepiandrosterone as an enhancer of functional recovery following crush injury to rat sciatic nerve. Microsurgery 22: 234-241, 2002.

28. Koenig HL, Gong WH and Pelissier P: Role of progesterone in peripheral nerve repair. Rev Reprod 5: 189-199, 2000.

29. Koenig HL, Schumacher M, Ferzaz B, et al: Progesterone synthesis and myelin formation by Schwann cells. Science 268 1500-1503, 1995.

30. Lin LF, Doherty DH, Lile JD, Bektesh S and Collins F: GDNF: a glial cell line-derived neurotrophic factor for midbrain dopaminergic neurons. Science 260: 1130-1132, 1993.

31. Lin LF, Zhang TJ, Collins F and Armes LG: Purification and initial characterization of rat B49 glial cell line-derived neurotrophic factor. J Neurochem 63: 758-768, 1994.

32. Duarte EP, Curcio M, Canzoniero LM and Duarte CB: Neuroprotection by GDNF in the ischemic brain. Growth Factors 30: 242-257, 2012

33. Henderson CE, Phillips HS, Pollock RA, et al: GDNF: a potent survival factor for motoneurons present in peripheral nerve and muscle. Science 266: 1062-1064, 1994.

34. Arenas E, Trupp M, Akerud P and Ibanez CF: GDNF prevents degeneration and promotes the phenotype of brain noradrenergic neurons in vivo. Neuron 15: 1465-1473, 1995.

35. Trupp M, Ryden M, Jornvall H, Funakoshi H, Timmusk T, Arenas E and Ibanez CF: Peripheral expression and biological activities of GDNF, a new neurotrophic factor for avian and mammalian peripheral neurons. J Cell Biol 130: 137-148, 1995.

36. Georgievska B, Kirik D, Rosenblad C, Lundberg C and Bjorklund A: Neuroprotection in the rat Parkinson model by intrastriatal GDNF gene transfer using a lentiviral vector. Neuroreport 13: 75-82, 2002.

37. Sun B, Hui GZ, Guo LH and Reiser J: Dopaminergic trophism after intrastriatal injection of lentivirus-transferred GDNF in Parkinson rat model. Sheng Wu Hua Xue Yu Sheng Wu Wu Li Xue Bao (Shanghai) 35: 937-940, 2003.

38. Saavedra A, Baltazar G and Duarte EP: Driving GDNF expression: the green and the red traffic lights. Prog Neurobiol 86: 186-215, 2008.
39. Behrsing HP and Vulliet PR: Purinergic and calcium-mediated enhancement of NGF-induced neurite expression in PC12 cells. Proc West Pharmacol Soc 42: 59-62, 1999.

40. Behrsing HP and Vulliet PR: Mitogen-activated protein kinase mediates purinergic-enhanced nerve growth factor-induced neurite outgrowth in PC12 cells. J Neurosci Res 78: 64-74, 2004.

41. D'Ambrosi N, Murra B, Cavaliere F, Amadio S, Bernardi G, Burnstock $\mathrm{G}$ and Volonte C: Interaction between ATP and nerve growth factor signalling in the survival and neuritic outgrowth from PC12 cells. Neuroscience 108: 527-534, 2001.

42. Soustiel JF, Zaaroor M, Vlodavsky E, Veenman L, Weizman A and Gavish M: Neuroprotective effect of Ro5-4864 following brain injury. Exp Neurol 214: 201-208, 2008.

43. Mills CD, Bitler JL and Woolf CJ: Role of the peripheral benzodiazepine receptor in sensory neuron regeneration. Mol Cell Neurosci 30: 228-237, 2005.

44. Akwa Y, Schumacher M, Jung-Testas I and Baulieu EE: Neurosteroids in rat sciatic nerves and Schwann cells. C R Acad Sci III 316: 410-414, 1993.

45. Ivanova T, Karolczak M and Beyer C: Estradiol stimulates GDNF expression in developing hypothalamic neurons. Endocrinology 143: 3175-3178, 2002.

46. Paratcha G and Ledda F: GDNF and GFRalpha: a versatile molecular complex for developing neurons. Trends Neurosci 31: 384-391, 2008.

47. Sariola $\mathrm{H}$ and Saarma M: Novel functions and signalling pathways for GDNF. J Cell Sci 116: 3855-3862, 2003.

48. Paratcha G, Ibanez CF and Ledda F: GDNF is a chemoattractant factor for neuronal precursor cells in the rostral migratory stream. Mol Cell Neurosci 31: 505-514, 2006.

49. Nielsen J, Gotfryd K, Li S, et al: Role of glial cell line-derived neurotrophic factor (GDNF)-neural cell adhesion molecule (NCAM) interactions in induction of neurite outgrowth and identification of a binding site for NCAM in the heel region of GDNF. J Neurosci 29: 11360-11376, 2009.

50. Enomoto H: Regulation of neural development by glial cell line-derived neurotrophic factor family ligands. Anat Sci Int 80: 42-52, 2005.

51. Wissel K, Stöver T, Hofmann NS, et al: Fibroblast-mediated delivery of GDNF induces neuronal-like outgrowth in PC12 cells. Otol Neurotol 29: 475-481, 2008.

52. Micallef J, Soubrouillard C, Guet F, Le Guern ME, Alquier C, Bruguerolle B and Blin O: A double blind parallel group placebo controlled comparison of sedative and mnesic effects of etifoxine and lorazepam in healthy subjects [corrected]. Fundam Clin Pharmacol 15: 209-216, 2001.

53. Nguyen N, Fakra E, Pradel V, et al: Efficacy of etifoxine compared to lorazepam monotherapy in the treatment of patients with adjustment disorders with anxiety: a double-blind controlled study in general practice. Hum Psychopharmacol 21: 139-149, 2006. 